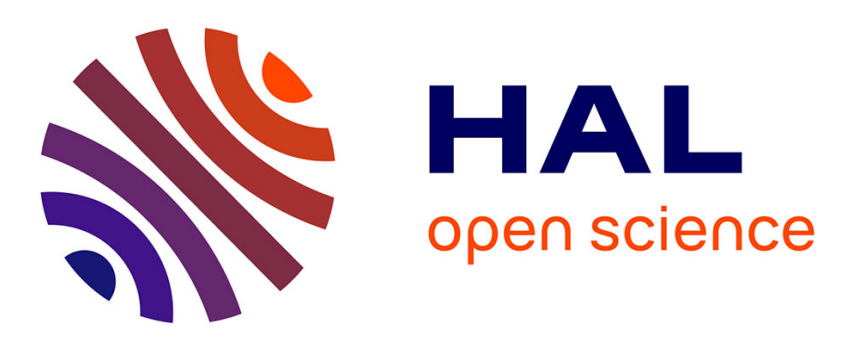

\title{
Effect of the developed temperature field on the molecular interdiffusion at the interface in infrared welding of polycarbonate composites
}

Andre Chateau Akue Asseko, Benoît Cosson, Eric Lafranche, Fabrice Schmidt, Yannick Le Maoult

\section{To cite this version:}

Andre Chateau Akue Asseko, Benoît Cosson, Eric Lafranche, Fabrice Schmidt, Yannick Le Maoult. Effect of the developed temperature field on the molecular interdiffusion at the interface in infrared welding of polycarbonate composites. Composites Part B: Engineering, 2016, 97, p. 53-61. 10.1016/j.compositesb.2016.04.064 . hal-01609024

\section{HAL Id: hal-01609024 https://hal.science/hal-01609024}

Submitted on 2 Jul 2018

HAL is a multi-disciplinary open access archive for the deposit and dissemination of scientific research documents, whether they are published or not. The documents may come from teaching and research institutions in France or abroad, or from public or private research centers.
L'archive ouverte pluridisciplinaire HAL, est destinée au dépôt et à la diffusion de documents scientifiques de niveau recherche, publiés ou non, émanant des établissements d'enseignement et de recherche français ou étrangers, des laboratoires publics ou privés. 


\title{
Effect of the developed temperature field on the molecular interdiffusion at the interface in infrared welding of polycarbonate composites
}

\author{
André Chateau Akué Asséko a, b, *, Benoît Cosson ${ }^{a}$, Éric Lafranche ${ }^{a}$, Fabrice Schmidt ${ }^{\text {b }}$, \\ Yannick Le Maoult ${ }^{\mathrm{b}}$ \\ ${ }^{a}$ Mines Douai, Department of Polymers and Composites Technology \& Mechanical Engineering, 941 rue Charles Bourseul, CS 10838, F-59508 Douai Cedex, \\ France \\ ${ }^{\mathrm{b}}$ Université de Toulouse, Mines Albi, ICA (Institut Clément Ader), Campus Jarlard, F-81013 Albi cedex 09, France
}

\section{A B S T R A C T}

In this study, the effects of the welding temperature field developed during the infrared assembly process on the joining properties of glass fiber reinforced polycarbonate/unreinforced polycarbonate with carbon black were investigated. The temperature field and the contact time govern together the quality of the adhesion at the welding interface. The effect of the semi-transparent glass fiber reinforced polycarbonate composite/unreinforced polycarbonate composite with carbon black interface was quantified in term of quadratic distance of diffusion or diffusion depth through the welding interface. First, an experimental setup for the temperature measurement was performed using infrared camera, during infrared welding of materials joints. Then, numerical simulations using commercial FEM software COMSOL Multiphysics ${ }^{\circledR}$ allows simulating the temperature field by implementing a developed 3D heat source, in order to determine the generated heat source at the welding interface and the variation of the temperature field during the infrared welding process. The microstructural characterizations were investigated in order to inspect the welding zones quality and to observe their failure modes. The diffusion theory has then been applied to calculate the variation of the quadratic distance of diffusion versus time at different locations. The complete self-diffusion is supposed occurring only at temperature above the polycarbonate glass transition temperature $\left(140^{\circ} \mathrm{C}\right)$ and with a quadratic distance of diffusion superior to the mean square end-to-end distance. At the welding interface, the calculation of the quadratic distance of diffusion showed that a complete self-diffusion has not yet been reached. A perfect cohesion was not established.

Keywords:

Infrared welding

Polycarbonate

Molecular diffusion

Continuous glass fibre composite

Thermal modelling

Microstructural analysis

\section{Introduction}

Our previous studies [1-3] investigated a global analytical model (refraction and absorption phenomena) for modeling of transmission laser/infrared welding process in thermoplastic composites. This model allows describing the attenuation of laser

\footnotetext{
* Corresponding author. Mines Douai, Department of Polymers and Composites Technology \& Mechanical Engineering, 941 rue Charles Bourseul, CS 10838, F59508 Douai Cedex, France.

E-mail addresses: andre.akue.asseko@mines-douai.fr (A.C. Akué Asséko), benoit. cosson@mines-douai.fr (B. Cosson), eric.lafranche@mines-douai.fr (É. Lafranche), fabrice.schmidt@mines-albi.fr (F. Schmidt), yannick.lemaoult@mines-albi.fr (Y. Le Maoult).
}

beam, the prediction of heat source in laser welding process thermal simulation in the case of UD thermoplastic composite as well as the evolution of the three dimensional temperature field during the welding process.

The part performances in the case of the association of two or more materials depend not only of the own properties of each material but also on their interface and/or interphase properties directed by the assembly process (thermal or chemical assembly). In the case of melted assembly of miscible thermoplastics (thermal welding or co-molding processes), the polymer adhesion will be considered depending of the contact time, the surface wettability and chain diffusions [4,5].

More than one mechanism contributes to the adhesion of polymers. The mechanical adhesion, the electrical theory, the 


\begin{tabular}{|c|c|c|c|}
\hline \multicolumn{2}{|c|}{ Nomenclature } & \multirow{2}{*}{$\begin{array}{l}\rho_{\mathrm{v}} \\
\mathrm{h}_{\mathrm{c}} \\
\mathrm{h}_{\mathrm{r}}\end{array}$} & \multirow{2}{*}{$\begin{array}{l}\text { Density }\left(\mathrm{kg} / \mathrm{m}^{3}\right) \text {, } \\
\text { Convection heat transfer coefficient }\left(\mathrm{W} / \mathrm{m}^{2} \mathrm{~K}\right) \\
\text { Radiative heat transfer coefficient }\left(\mathrm{W} / \mathrm{m}^{2} \mathrm{~K}\right)\end{array}$} \\
\hline$D$ & Self-diffusion $\left(\mathrm{m}^{2} / \mathrm{s}\right)$ & & \\
\hline$\rho_{\mathrm{y}}$ & Density $\left(\mathrm{kg} / \mathrm{m}^{3}\right)$ & $\begin{array}{l}\Lambda_{\mathrm{r}} \\
\mathrm{T}_{0}\end{array}$ & Ambient temperature \\
\hline $\mathrm{x}, \mathrm{y}, \mathrm{z}$ & Space variables & $\varepsilon$ & Material emissivity \\
\hline $\mathrm{T}$ & Temperature $\left({ }^{\circ} \mathrm{C}\right)$ & $\sigma_{\mathrm{b}}$ & Black body emission coefficient $\left(5.67 \times 10^{-8} \mathrm{~W} / \mathrm{m}^{2} \mathrm{~K}^{4}\right)$ \\
\hline $\mathrm{I}_{\mathrm{o}}$ & Laser power $(\mathrm{W})$ & $\mathrm{R}$ & Virtual gas constant $(\mathrm{g} / \mathrm{mol} . \mathrm{K})$ \\
\hline$r_{\text {spot }}$ & Initial laser beam radius $(\mathrm{m})$ & $\mathrm{M}_{\mathrm{e}}$ & Molecular weight of entanglement $(\mathrm{g} / \mathrm{mol})$ \\
\hline$\sigma_{\mathrm{o}}$ & Spatial shape parameter of the initial laser beam (m) & $\mathrm{M}_{\mathrm{c}}$ & Critical molecular weight $(\mathrm{g} / \mathrm{mol})$ \\
\hline$\sigma_{\mathrm{x}}$ & Scattering standard deviation (m) & $\mathrm{M}_{\mathrm{w}}$ & Molecular weight (g/mol) \\
\hline A & Optical scattering coefficient of the semi-transparent & $\eta_{0}$ & Newtonian viscosity (Pa.s) \\
\hline & composite $\left(\mathrm{m}^{-1}\right)$ & $\eta_{0, M_{c}}$ & Viscosity at the critical molecular (Pa.s) \\
\hline K & Absorption coefficient $\left(\mathrm{m}^{-1}\right)$ & $R_{g}$ & Mean square end to end distance of the chain (m) \\
\hline$\alpha_{\mathrm{a}}$ & Absorption factor of the absorbent composite & $\mathrm{G}_{N}^{0}$ & Plateau modulus $(\mathrm{Pa})$ \\
\hline$\rho_{\mathrm{a}}$ & Reflection coefficient of the absorbent material & $l^{i^{v}}$ & Quadratic distance of diffusion $\left(\mathrm{m}^{2}\right)$ \\
\hline & Reflection coefficient of the semi-transparent material & $\mathrm{T}_{\mathrm{g}}$ & Glass transition temperature $\left({ }^{\circ} \mathrm{C}\right)$ \\
\hline $\mathrm{I}(\mathrm{x}, \mathrm{y})$ & Surface laser beam power at the interface $\left(\mathrm{W} / \mathrm{m}^{2}\right)$ & PC & Polycarbonate \\
\hline $\mathrm{Q}(\mathrm{x}, \mathrm{y}, \mathrm{z})$ & Heat source $\left(\mathrm{W} / \mathrm{m}^{3}\right)$ & $\mathrm{CB}$ & Carbon black \\
\hline$\rho_{\lambda}$ & Reflectivity coefficient & $\mathrm{t}$ & Time $(s)$ \\
\hline$\underline{k}$ & Orthotropic thermal conductivity tensor $(\mathrm{W} / \mathrm{m} . \mathrm{K})$ & $d_{t}$ & Semi-transparent part thickness (m) \\
\hline
\end{tabular}

wettability model, the diffusion or inter-diffusion model, the chemical link theory are generally used to explain the polymer adhesion, each of them being applicable in a specific domain depending of the nature of the welded polymers and the assembly conditions $[5,6]$.

In the case of the adhesion of two miscible polymers, the total melting of the whole surface is necessary for the development of the diffusion mechanism [7,8]. The adhesion is then characterized by molecular chain entanglement. The molecular aspect at the interface during the diffusion can be described by the reptation model developed by De Genne $[9,10]$ or by the simplified model of the minor chain [11,12] (Fig. 1).

At the origin $(t=0)$ the molecular contact is achieved at the interface, the reptation of the chain end segments can start $(t=1)$, at $\mathrm{t}=2$ only the minor chains contribute to the interdiffusion, finally when the time is close to the reptation time or relaxation time, the chain entanglements are achieved.

Finally the adhesion by interdiffusion or self-diffusion is based on two fundamental criteria: the thermodynamic criterion, in other words the polymer miscibility and the kinetic criterion directed by the molecule mobility depending on the temperature, the contact time, the pressure, the nature and molecular mass of the polymers $[7,13,14]$. This concept of interdiffusion widely described in the case of co-extrusion process, can also be considered as the illustration of thermoplastic welding at molecular level [15-17]. The weld strength develops as the polymer chains diffuse across the interface and lasts up to the reptation or relaxation time according to the schematic representation illustrated in Fig. 2 [11].

The theory of healing has been extensively studied by Wool and

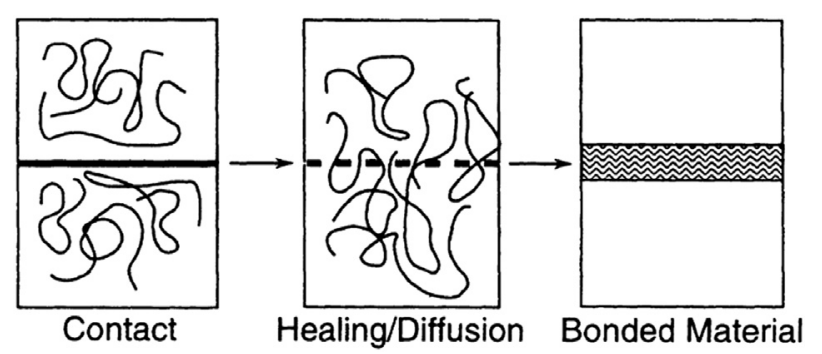

Fig. 2. Steps involved in fusion bonding of thermoplastic surfaces [11].

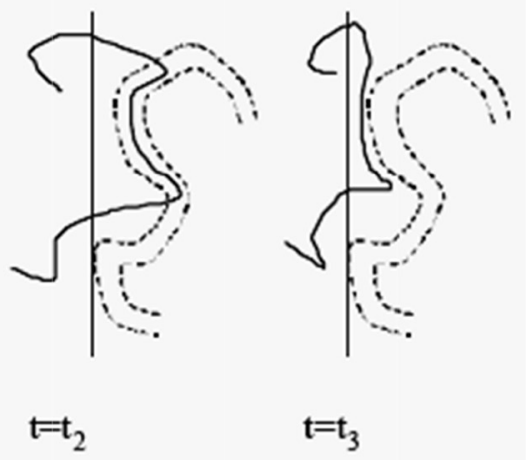

$$
0<\mathrm{t}_{1}<\mathrm{t}_{2}<\mathrm{t}_{\text {rep }}<\mathrm{t}_{3}
$$

Fig. 1. Diffusion of polymer chains across the interface (reptation theory) $[9,10]$. 
O'Connor [18]. They consider healing to occur in five stages: (a) surface rearrangement, (b) surface approach, (c) wetting, (d) diffusion, and (e) randomization. Rearrangement and surface approach account for surface changes, chemical reactions, molecular orientation changes at the surface, and the time-dependent contact of different parts of the surface. Once these two stages are complete, the interdiffusion of the polymer chains across the interface can occur as defined by wetting and diffusion stages. The randomization stage refers to the conformational relaxations contributing to equilibrium at the healed interface. Regarding the infrared welding of two compatible polymers, the total melting of the surface is necessary to the development of the interdiffusion mechanism [19]. A good adhesion is normally obtained when the molecules of the two materials diffuse between them to create molecular entanglement at the interface [8].

On the bases of our previous works, this present study focuses on the effects of the welding temperature field developed during the assembly process on the joining properties of glass fiber reinforced polycarbonate/polycarbonate composite. The temperature field and the contact time govern together the quality of the adhesion at the welding interface. For this purpose, the diffusion theory has then been applied according to the Graessley's analytic method [20].

\section{Experimental}

\subsection{Materials}

The materials studied were unidirectional (UD) $40 \mathrm{wt} \%$ glass fiber reinforced polycarbonates (PC, Makrolon 2405, Bayer Material Science, Germany: $\mathrm{M}_{\mathrm{w}}=38,700 \mathrm{~g} \mathrm{~mol}^{-1}$ ). The absorbent polycarbonate composite was added of $0.0243 \mathrm{wt} \%$ of carbon black.

\subsection{Composite materials processing}

The UD composites were prepared by compression molding using the film stacking process. $0.3 \mathrm{~mm}$ thick PC films were first obtained by cast-extrusion process at a temperature of $300^{\circ} \mathrm{C}$ using a Collin single-screw extruder (Germany). Vacuum dried PC films $\left(120^{\circ} \mathrm{C}\right.$ for $\left.4 \mathrm{~h}\right)$ and UD glass fiber were then placed alternately in an aluminum mold. The compression molding was achieved in a Dolouet press (France) at $300{ }^{\circ} \mathrm{C}$ under 50 bars.

\subsection{Infrared welding process}

Infrared welding of composites involves two joining parts: one semi-transparent to the IR wavelengths and the other part is absorbent in the same wavelengths. The two parts are positioned together before the welding. Surface treatments are not need as in the gluing process. The infrared beam energy is transmitted through the semi-transparent material and is absorbed within the surface of the second material (Fig. 3). The bonding between the two parts allows the heating of the semi-transparent part by thermal conduction. Thus, melting and fusion of both materials interface occurs (the bonding between the two parts occurs when $\mathrm{T}>\mathrm{T}_{\mathrm{g}}$ in this area). The energy is deposited at the interface in a localized volume causing the formation of a weld zone.

The experimental device, mentioned below (Fig. 4), is used for the temperature measurement. A halogen lamp MAZDA GY.6.35 (nominal power: $50 \mathrm{~W}, 12 \mathrm{~V}$ ) is focused by a precision Edmund Optics ellipsoidal reflector with $115 \mathrm{~mm}$ for the diameter and two focal points (17 mm and $272 \mathrm{~mm}$ ). When a light source is placed at the first focal point, the source will refocus at the second focal point. The protected aluminum coating features broadband high reflection through the visible and IR spectra (90\%); it comes to heat the interface of the two materials. The temperature field on the back surface of the absorbent material is measured using again the CS 325 FLIR infrared camera [7.5-13.5 $\mu \mathrm{m}$ ]. The contact pressure generated by the tightening of each clip is like a force of $16 \mathrm{~N}$ distributed on a line of $8 \mathrm{~mm}$. This force was measured using a FUTEK micro force sensor.

Fig. $5 \mathrm{a}$ and $\mathrm{b}$ show respectively the measured thermal image on the back of the absorbent parts and the evolution (center) of the average temperature field measured for about $20 \mathrm{~s}$ of heating process, for three tests. The error bars represent the measured minimum and maximum values during the tests.

\subsection{Heat source at the welding interface}

To determine the generated heat source at the welding interface, the profile of the distribution of the total transmitted power of the laser/infrared beam (the total power after penetrating into the semi-transparent composite and reaching the welding interface) is used [1-3]. For a Gaussian laser beam, the distribution of the total power of the laser/infrared inward beam in the case of UD semitransparent composite is:

$$
\begin{aligned}
\mathrm{I}(\mathrm{x}, \mathrm{y})= & \left(1-\rho_{\mathrm{t}}\right) \frac{\mathrm{I}_{\mathrm{o}} \times \mathrm{e}^{-\mathrm{Ad} d_{\mathrm{t}}}}{2 \pi \sigma_{\mathrm{o}} \sqrt{\left(\sigma_{\mathrm{x}}(\mathrm{z})^{2}+\sigma_{\mathrm{o}}^{2}\right)}} \\
& \times \mathrm{e}^{-\left(\frac{\mathrm{x}^{2}}{2\left(\sigma_{\left.\mathrm{x}()^{2}+\sigma_{0}^{2}\right)}+\frac{\mathrm{y}^{2}}{2 \sigma_{\mathrm{o}}^{2}}\right.}\right)} \text { for all } \mathrm{x} \in \Omega_{\mathrm{t}}
\end{aligned}
$$

where $\mathrm{x}$ (fiber direction), $\mathrm{y}$ (transverse direction of fiber) and $\mathrm{z}$ (thickness direction) are the space variables, $\left(\sigma_{0}=r_{\text {spot }} / 3\right.$ with $r_{\text {spot }}$ the initial focused spot radius), $\sigma_{\mathrm{x}}$ is a function of the thickness, refraction index of matrix and fiber volume fraction and micros structural arrangement.
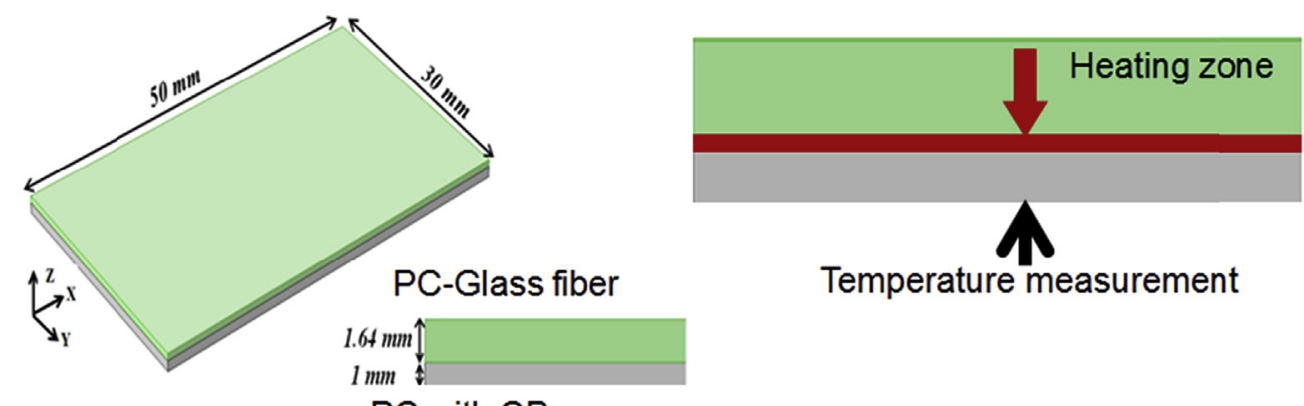

$\mathrm{PC}$ with $\mathrm{CB}$

Fig. 3. Schematic representation of the samples. 


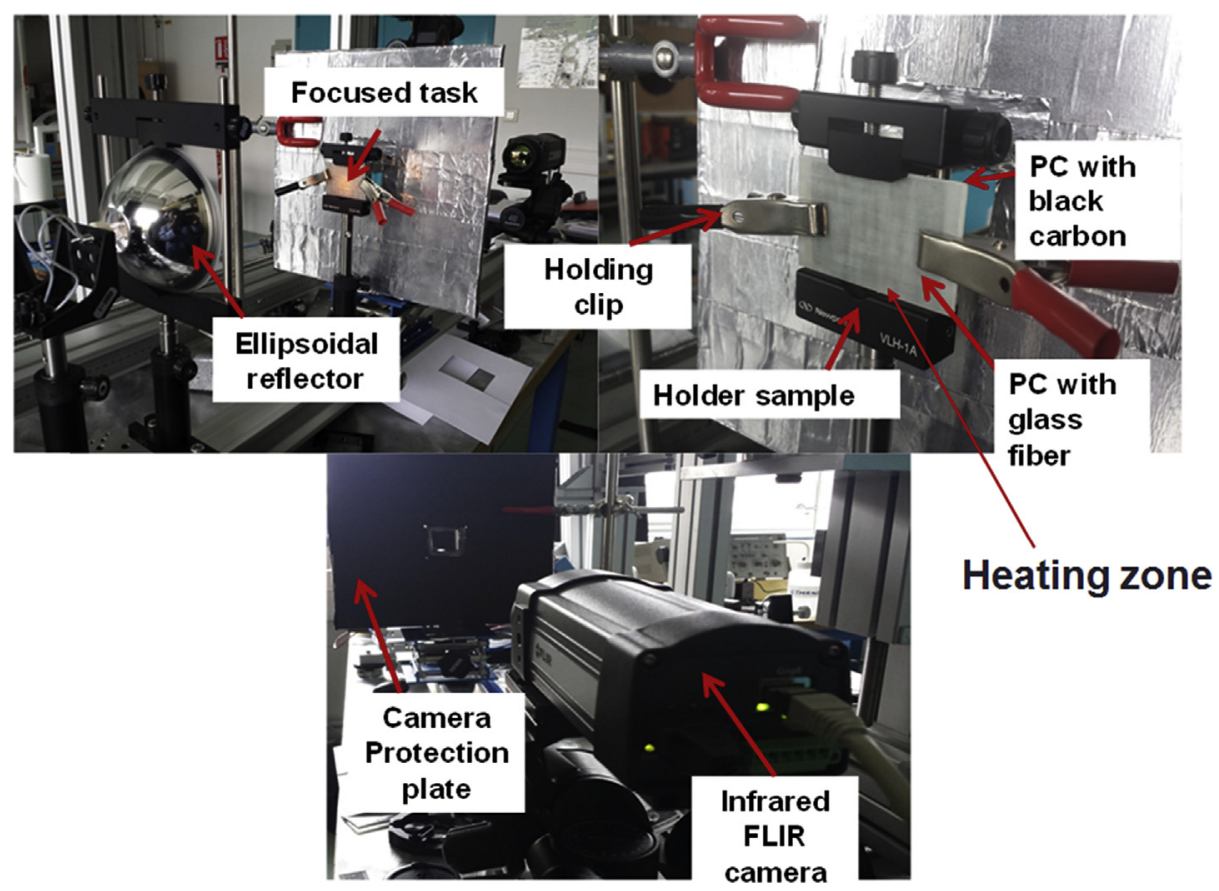

Fig. 4. Infrared welding system.

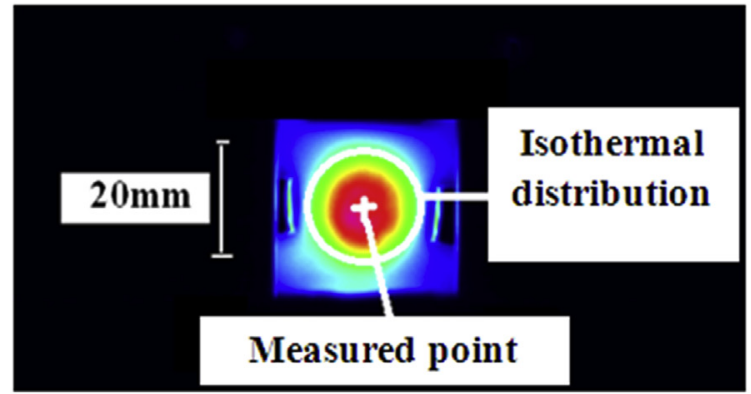

a)

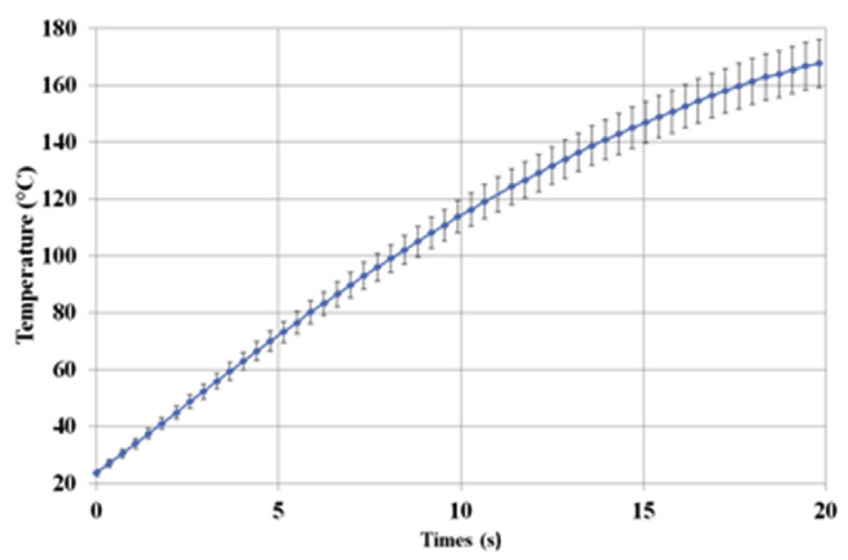

b)

Fig. 5. Measured thermal image (a) - Temperature variation on the back surface of absorbent part (b).

In the absorbent part, a high absorption of laser beam radiation is considered, according to Beer-Lambert's law, and a heat transfer
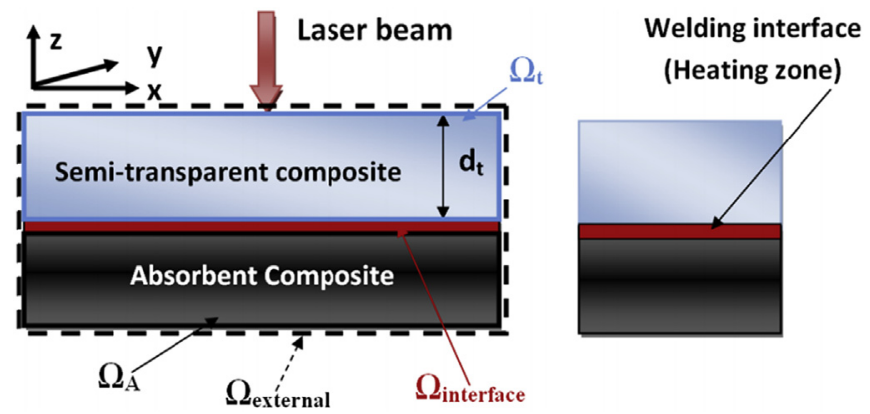

Fig. 6. Semi-transparent and absorbent composites coupling. by thermal conduction between the two parts. The heat source in the case of an assumed transparent and absorbent composites coupling is described by the following equations (Fig. 6):

$\mathrm{Q}(\mathrm{x}, \mathrm{y}, \mathrm{z})=\left\{\begin{array}{cc}0 & \text { for } \mathrm{z}<d_{t} \\ I(\mathrm{x}, \mathrm{y}) \times \mathrm{K} \times \mathrm{e}^{-\mathrm{K} \times\left(\mathrm{z}-d_{t}\right)} & \text { for } \mathrm{z}>d_{t}\end{array}\right.$

where $d_{t}$ is the thickness of the semi-transparent composite. In our study, recall that the absorption in the strongly, scattering semitransparent composite is neglected i.e. assuming ideal transparent material and we consider just a strong absorption at the surface of the absorbent composite (welding interface) and heat transfer by thermal conduction in both composites. The absorption coefficient $\mathrm{K}$ is considered infinite. That is to model the heat source in surface flux (surface absorption) and the equation below is simplified as follows: 
$\mathrm{Q}(\mathrm{x}, \mathrm{y})=\left(1-\rho_{\mathrm{t}}\right) \times \alpha_{\mathrm{a}} \mathrm{I}(\mathrm{x}, \mathrm{y})$

With $\alpha_{\mathrm{a}}=1-\rho_{\mathrm{a}}$ (absorption factor of the absorbent composite), $\rho_{t}$ reflection coefficient of the semi-transparent composite.

The global analytical model (coupled optical-thermal model) is represented by the coupling of the two parts. Optical model (semitransparent material): characterized by the surface distribution of the infrared beam at the welding interface in the plane system coordinate $(\mathrm{x}, \mathrm{y})$ and the thermal model (absorbent material): characterized by surface and core absorption. Knowing the generated heat source, the calculation of the temperature field around the welding interface is performed numerically using a finite element model solving heat transfer eq. (3). A perfect contact between the two components subjected to welding is assumed.

$\vec{\nabla} \cdot(\underline{\underline{k}} \vec{\nabla} T)+Q(x, y, z)=\rho_{v} c_{p}(T) \frac{\partial T}{\partial t}$ for all $\mathrm{x} \in \Omega_{\mathrm{A}}$

For the heat transfer boundary condition between the two components and the surrounding medium, the boundary condition can be expressed by:

$-k \vec{\nabla} T \cdot \overrightarrow{\mathrm{n}}=h_{c}\left(T_{\mathrm{s}}-T_{0}\right)+\varepsilon \sigma_{b}\left(T_{s}^{4}-T_{0}^{4}\right)$ for all $\mathrm{x} \in \Omega_{\text {external }}$

where $\vec{n}$ is the outward normal vector of the surface, $T_{0}=293.15 \mathrm{~K}$ is the ambient temperature and $h_{c}$ is the convective heat transfer coefficient $\left(5.736 \mathrm{~W} \mathrm{~m}^{-2} \mathrm{~K}\right.$ ). This value is calculated by relying on correlations of the exchange coefficients for a planar plate cooled on its top face. In order to determine the temperature field during the laser/infrared welding process, thermophysical and optical properties of the materials to be welded are required as input parameters to model the thermal process properly (previous study [3]).

\subsection{Mechanical testing}

The tensile tests of the welded glass fiber reinforced PC/unreinforced black PC samples were performed on a standard tensile machine (Model 1185 Instron, UK) on 3 samples (PC dimensions of $140 \times 21 \mathrm{~mm}$ with a welding area of $30 \times 21 \mathrm{~mm}$ ) at a constant cross-head speed of $2 \mathrm{~mm} \mathrm{~min}^{-1}$. The tensile (both polycarbonate samples) or shearing (polycarbonate welding area) strength was then calculated. All the samples were first dried at $50{ }^{\circ} \mathrm{C}$ during $168 \mathrm{~h}$ before testing. The welded sample was tested in tensile mode (shear loading of the weldline).

\subsection{Rheological characterizations of Makrolon 2405}

The master curves at $190{ }^{\circ} \mathrm{C}$ of polycarbonates (natural Makrolon 2405 and CNT filled Makrolon 2405) were carried out by a strain-controlled oscillatory shear rheometer (Haake Mars III, Thermo Scientific, Germany) equipped with parallel plates of $35 \mathrm{~mm}$ diameter (Fig. 7b). Linear domains of the material were identified from the strain sweep test run from 0.01 to $10^{4} \mathrm{rad} \mathrm{s}^{-1}$ at a strain of $1 \%$ (this value being the linear domain) and temperature of $190^{\circ} \mathrm{C}, 200^{\circ} \mathrm{C}, 210^{\circ} \mathrm{C}, 220^{\circ} \mathrm{C}$ and $230^{\circ} \mathrm{C}$ to determine $\mathrm{G}^{\prime}, \mathrm{G}^{\prime \prime}$ and $\eta$ (Fig. $7 \mathrm{a}$ and $\mathrm{b}$ ).

\section{Results and discussion}

\subsection{Optical and thermal results}

The Fig. 8 shows the Gaussian shape distribution of the total

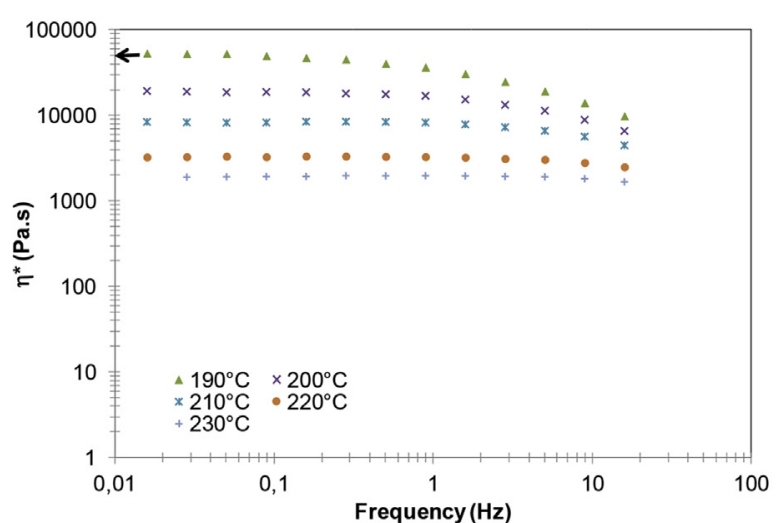

(a)

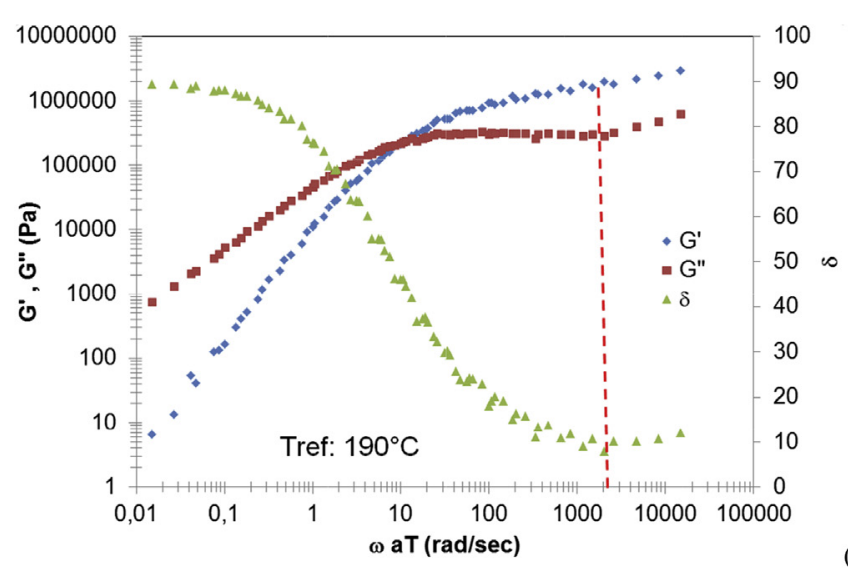

(b)

Fig. 7. Complex viscosity versus frequency (a) and master curves at $190{ }^{\circ} \mathrm{C}$ (b) for Makrolon ${ }^{\circledR}$ PC 2405.

power of the infrared inward beam in the case of UD semitransparent composite (the absorbed powers at the welding interface).

The commercial FEM software COMSOL Multiphysics ${ }^{\circledR}$ was used to obtain the temperature field by implementing a developed 3D heat source. Fig. 9 shows the temperature field within the materials. The heat generated at irradiation zone is gradually transferred to surrounding material by effect of thermal conduction. We observe the impact on the exposure time for a good welding.

It also indicates that the maximum temperature $\left(179{ }^{\circ} \mathrm{C}\right)$ is reached to the inside of the absorbent part $\left(Z_{T \max }\right)$, not at the interface $\left(Z_{\mathrm{I}}\right)$. This is caused by the volume energy absorption in the absorbent material. This leads to an asymmetric distribution of geometry in the weld zone.

\subsection{Microstructural analysis of the weld zones}

In Fig. 10 (top) and (bottom), microscopic observations are performed on the welded joint. In the Fig. 1 (top), a cross section in the plane system coordinate $(\mathrm{z}, \mathrm{x})$ shows the welded zone in the welding interface. The formation of a weldline between the two materials is noticed. The average width of the weldline is about $45 \mu \mathrm{m}$.

In Fig. 10 (bottom), we carried out a debonding of the welded joint in order to observe its fracture surfaces (the failure was obtained manually). Two failure modes are noted. An adhesive failure which takes place at the welding interface and separating the two welded surfaces cleanly and without carry forward of matter from one surface to the other. However, on a cohesive failure, the two 


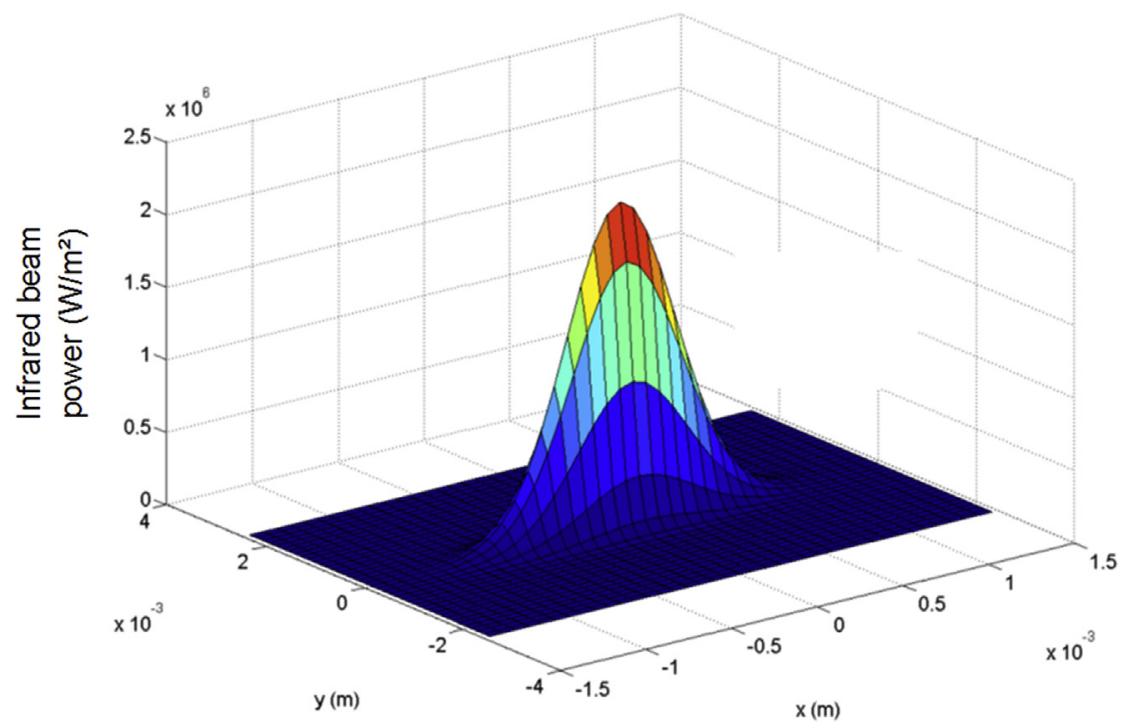

Fig. 8. Surface infrared/laser beam power at the welding interface $\left(\mathrm{W} / \mathrm{m}^{2}\right)$.

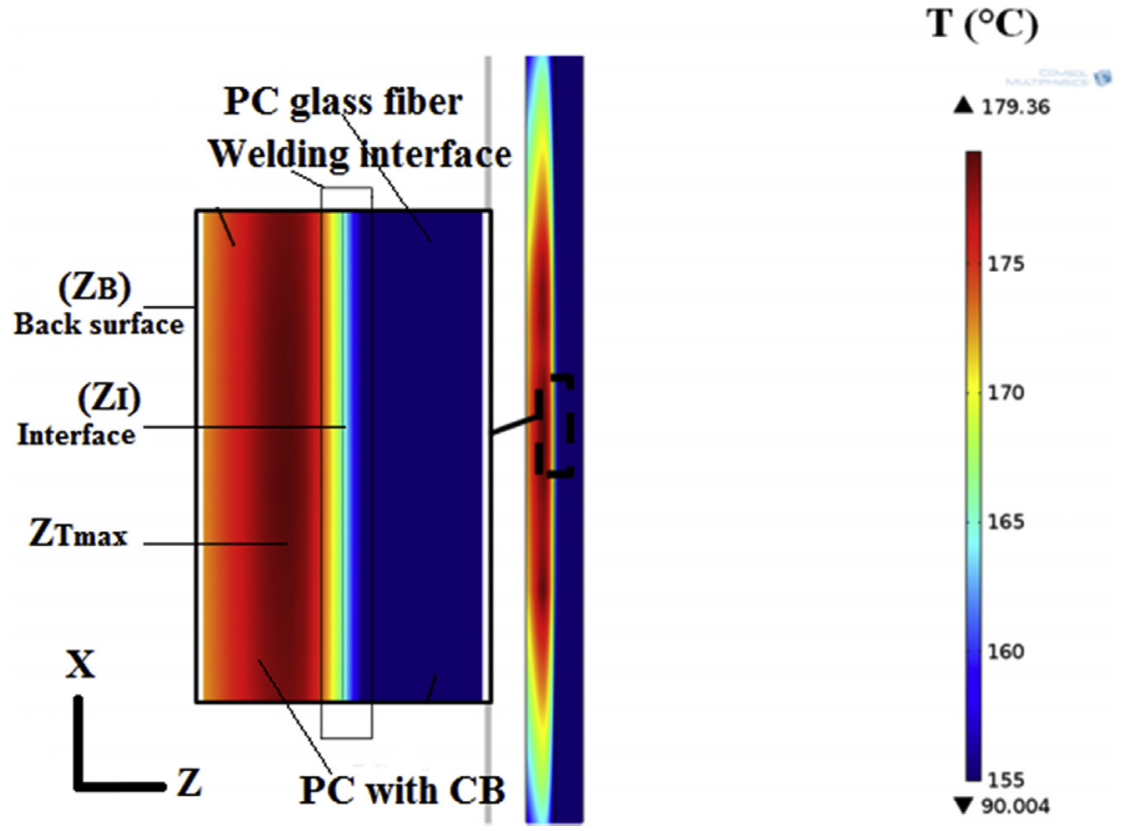

Fig. 9. Temperature field within the materials $(t=20 s)$.

welded parts are mixed up. This failure mode characterizes a good welding quality [21]. In Fig. 10 (bottom), are found the mixed PC glass fiber and PC with CB surfaces in some areas. Macromolecular structures on each side of the welding interface have been mixing in order to establish an entangled network. A cohesive failure of these welded materials is observed. This visual comparison provides the first information on the welding performed quality. The weldline which is observed by optical microscopy shows in fact, a good contact between the two melted composites parts and some irregular surfaces (no visible air cavities in particular). Moreover, the tensile mechanical evaluation of the welding area in shearing solicitation has shown a good performance of the joining zone because the break is occurred on the black polycarbonate part of the sample. The shear strength appeared superior to the tensile strength of the unreinforced black polycarbonate which was broken at 28.8 MPa (Fig. 11).

\subsection{Calculation of molecular self-diffusion at interface}

On the base of the works of De Gennes [9] and Edwards [10,22], Graessley [20] proposed a self-diffusion coefficient as a function of viscoelastic parameters of polymer:

$\left.\mathrm{D}=\frac{\mathrm{G}_{N}^{0}}{135} \frac{\rho R_{G} T}{\mathrm{G}_{N}^{0}}\right)^{2}\left(\frac{\left\langle R^{2}\right\rangle}{M_{w}}\right) \frac{M_{c}(T)}{\mathrm{M}_{w}^{2} \times \eta 0, M_{c}(T)}$

where $G_{N}^{0}$ is the plateau modulus, $\rho$ is the polymer density, $R_{G}$ is the virtual gas constant, $T$ is the absolute temperature, $\left\langle R^{2}\right\rangle$ is the mean square end-to-end distance of the chain, $\mathrm{M}_{\mathrm{w}}$ is the molecular weight, $\mathrm{M}_{\mathrm{C}}(\mathrm{T})$ is the critical molecular weight at the temperature $\mathrm{T}$, 


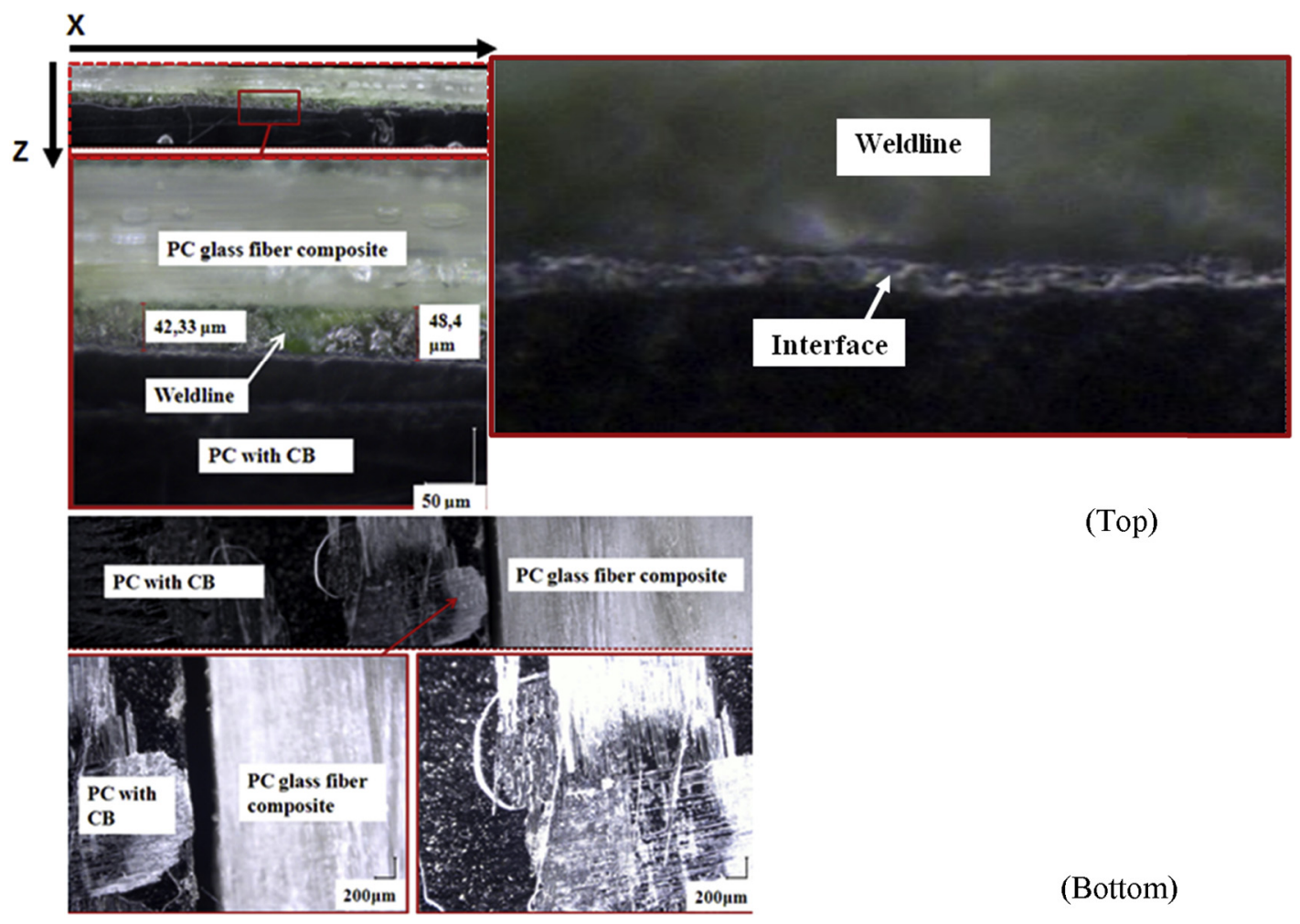

Fig. 10. Longitudinal section view (top) and the welded joint interface (bottom).

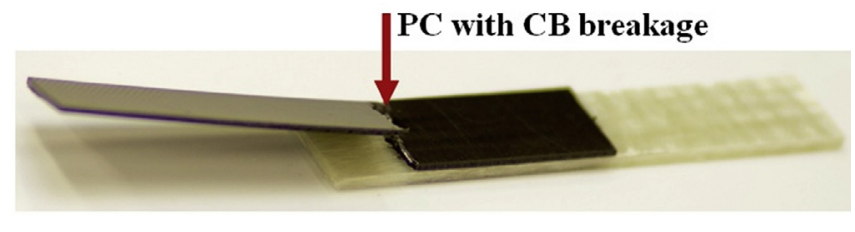

Fig. 11. Test result of the welded glass fiber reinforced PC/unreinforced black PC samples.

$\eta 0, \mathrm{M}_{\mathrm{c}}(\mathrm{T})$ is the viscosity at the critical molecular weight at the temperature $\mathrm{T}$.

The plateau modulus $\mathrm{G}_{\mathrm{N}}^{0}$ can be obtained from dynamic rheology considering the storage modulus at the frequency where $\tan \delta=G^{\prime \prime} / G$ ' reaches a minimum (Fig. 7 dotted line). The critical molecular weight $\mathrm{M}_{\mathrm{W}}$ is linked to the molecular weight of entanglement $\mathrm{M}_{\mathrm{e}}$ by the following equation [23]:

$\mathrm{M}_{c}(\mathrm{~T})=2 \times \mathrm{M}_{e}(\mathrm{~T})$

With:

$$
\mathrm{M}_{e}(\mathrm{~T})=\frac{\rho R T}{\mathrm{G}_{\mathrm{N}}^{0}}
$$

The mean end-to-end distance of chain is fixed at $\left\langle\mathrm{R}^{2}\right\rangle=4.06 \times$ $10^{-16} \mathrm{~m}^{2}$ at $463 \mathrm{~K}$ according to the relation with the molecular mass of the Makrolon $2405\left(<\mathrm{R}^{2}>/ \mathrm{M}_{\mathrm{W}}=1.05 \AA^{2} \mathrm{~mol} \mathrm{~g}^{-1}\right.$ [24]): The zero shear viscosity can be estimated by a WLF equation considering the effects of the temperature [25].

$$
\begin{aligned}
& \text { For } \mathrm{T} \geq \mathrm{T}_{\mathrm{g}} \quad \eta_{0}(\mathrm{~T})=D_{1} \cdot \exp \left[-\frac{A_{1}\left(T-T_{g}\right)}{A_{2}+\left(T-T_{g}\right)}\right] \\
& \text { For } \mathrm{T}<\mathrm{T}_{\mathrm{g}} \quad \eta_{0}(\mathrm{~T})=D_{1} \cdot \exp \left[\left(-\frac{A_{1} T_{g}}{A_{2}}\right) \cdot\left(\frac{\left(T-T_{g}\right)}{T}\right)\right]
\end{aligned}
$$

where $\left(D_{1}, A_{1}, A_{2}\right)$ are model parameters which have to be determined by curve fitting of experimental data.

In Table 1 , all the data and self-diffusion calculation of the Makrolon ${ }^{\circledR} 2405$ polycarbonate at $190^{\circ} \mathrm{C}$ are reported.

The self-diffusion coefficient depends on the thermo-dependent factors as the polymer temperature, the critical molecular weight, the Newtonian viscosity at the critical molecular mass. Coupling the calculation with temperature variation during the infrared welding stage of the parts, allows accessing to the variation of the selfdiffusion coefficient versus the welding time. Considering that the self-diffusion is only possible for a polymer temperature superior to the glass transition temperature $\mathrm{T}_{\mathrm{g}}\left(140{ }^{\circ} \mathrm{C}\right.$ according to Bayer Material Sciences source), the diffusion time can be determined when the temperature in the part reaches the $T_{g}$ of the polycarbonate. The quadratic distance of diffusion $\left\langle 1^{2}\right\rangle$ can be

\begin{tabular}{|c|c|c|c|}
\hline $\mathrm{G}_{N}^{0}$ & $1.614 \times 10^{6}$ & $\mathrm{M}_{e}(T)\left(\mathrm{g} \cdot \mathrm{mol}^{-1}\right)$ & 2861 \\
\hline$\rho\left(\right.$ g. $\left.m^{3}\right)$ & $1.2 \times 10^{6}$ & $\mathrm{M}_{c}\left(\mathrm{~g} \cdot \mathrm{mol}^{-1}\right)$ & 5723 \\
\hline$R\left(\mathrm{~J} \cdot \mathrm{mol}^{-1} \cdot \mathrm{K}^{-1}\right)$ & 8.314 & $\eta 0, M_{c}(T)($ Pa.s $)$ & 80 \\
\hline $\mathrm{M}_{w}\left(\mathrm{~g} \cdot \mathrm{mol}^{-1}\right)$ & $38.7 \times 10^{3}$ & $\eta 0(T)($ Pa.s $)$ & 53,350 \\
\hline$A_{1}(K)$ & 23 & $\left\langle R^{2}\right\rangle\left(m^{2}\right)$ & $4.06 \times 10^{-16}$ \\
\hline $\begin{array}{l}A_{2}(K) \\
\mathrm{D}\left(\mathrm{m}^{2} \mathrm{~s}^{-1}\right)=4 .\end{array}$ & $\begin{array}{l}51.6 \\
0^{-17}\end{array}$ & $D_{1}$ (Pas) & $4.42 \times 10^{9}$ \\
\hline
\end{tabular}

Table 1

All data for self-diffusion coefficient calculation. 


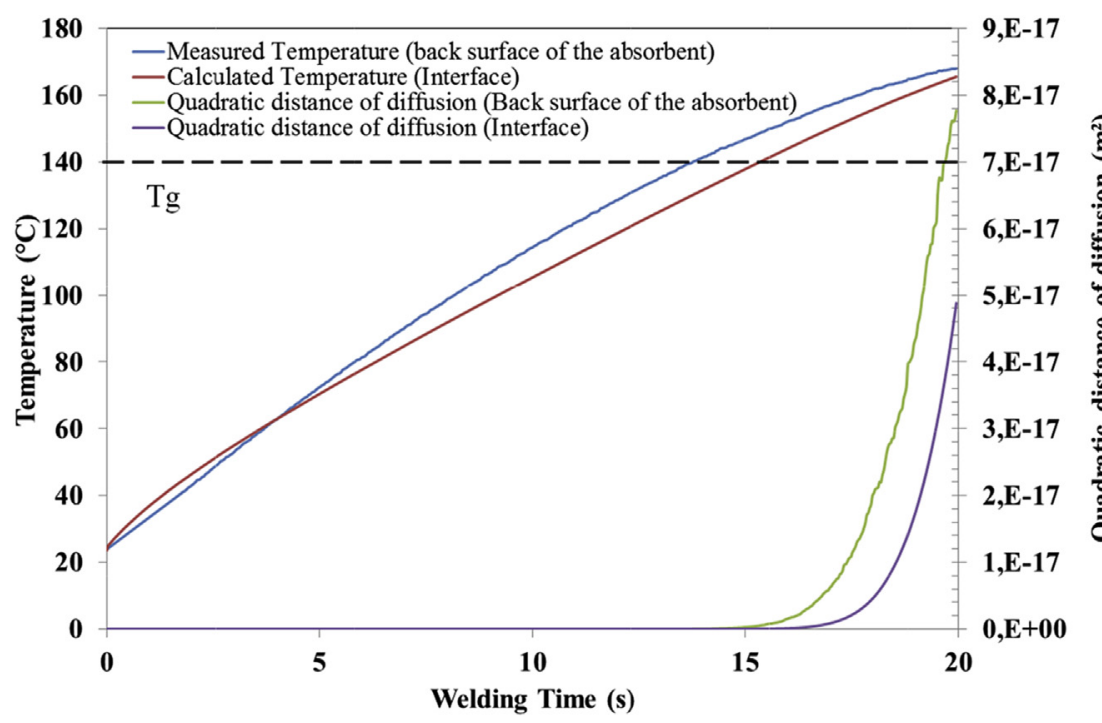

Fig. 12. Evolution of temperatures versus time: measured on the back surface of absorbent part - simulated at the interface and the respective quadratic distance of diffusion versus time.

expressed in function of the diffusion time by the expression:

$\left\langle 1^{2}\right\rangle=2 . D . t$

For a distance to the median plan $(\mathrm{z}=0)$, the quadratic distance of diffusion $\left(\left\langle 1^{2}\right\rangle_{z}\right)$ can be also expressed by the area under the Selfdiffusion coefficient (D) (eq. (6)) versus the diffusion time from the median plan ( $\mathrm{t}^{\mathrm{z}}$ diff) curves according to the equation (12).

$\left\langle 1^{2}\right\rangle_{\mathrm{z}}=2 \cdot \int_{0}^{t_{\text {diff }}^{z}} D(t) d t$

Furthermore, the self-diffusion can only occur at a quadratic distance of diffusion superior to the mean square end-to-end distance $\left(<\mathrm{R}^{2}>=4.06 \times 10^{-16} \mathrm{~m}^{2}\right)$. Below this limit, the probability of self-diffusion decreases rapidly.

Fig. 12 shows the evolution of quadratic distance of diffusion (calculated according to the Equation (11)) versus time at the two locations: the measured temperature variation on the center back surface of absorbent part ( $\left.T_{\text {back surface }}\right)$ and the simulated or calculated temperature at the interface. At the interface (Fig. 13), the quadratic distance of diffusion or the macromolecular depth of entanglement $\left(\left\langle 1^{2}\right\rangle_{z}\right)$ is $4.88 \times 10^{-17} \mathrm{~m}^{2}$ according to the equation (12). Thus, the necessary conditions for a complete self-diffusion have not yet been reached. A perfect cohesion is not established even if the first condition of a welding temperature realized above the glass transition temperature of the polycarbonate is achieved. The welding temperature should be increased to obtain a better cohesion of the welding interface and a perfect chain entanglement. The calculated quadratic distance of diffusion is also inferior to the mean square end-to-end distance of the polycarbonate at the referenced temperature $\left(4.88 \times 10^{-17} \mathrm{~m}^{2}<\mathrm{Rg}^{2}=4.06 \times{ }^{-16} \mathrm{~m}^{2}\right)$.

Fig. 13 shows also an increase of the diffusion probability under the interface $\left(Z_{\mathrm{Tmax}}=0.4 \mathrm{~mm}\right)$ due to the volume absorption phenomenon which leads an increase of the temperature revealed

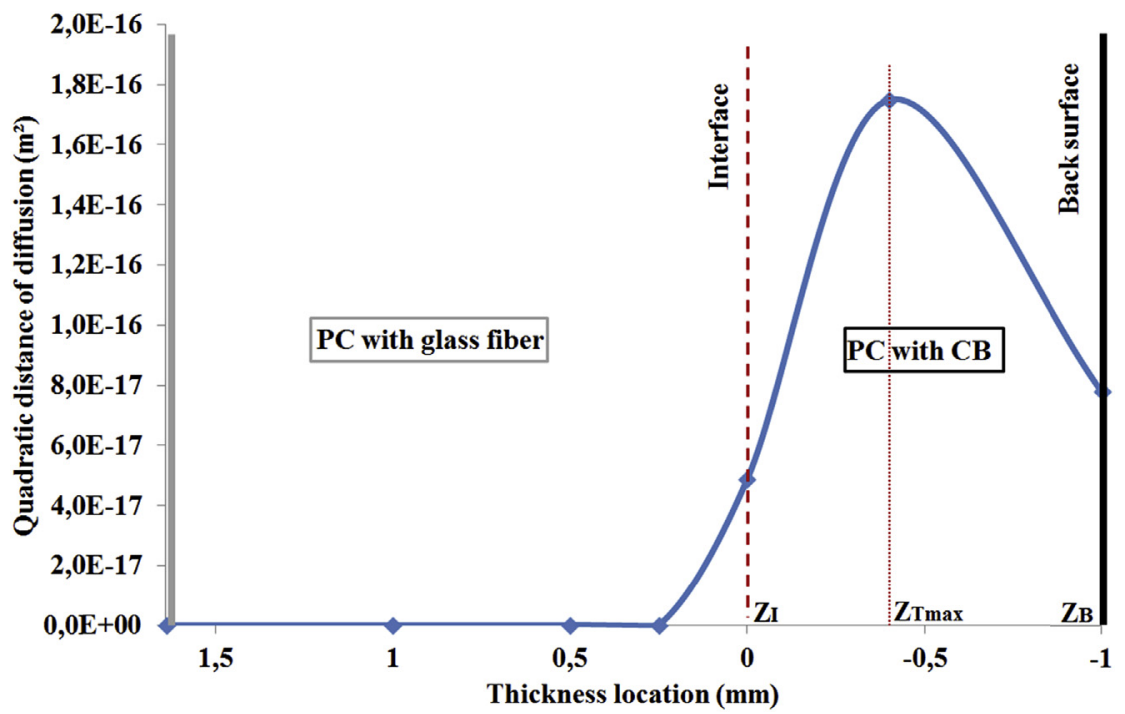

Fig. 13. Quadratic distance through the thickness. 
at this location (Fig. 9).

\section{Conclusion}

This present study was focused on the effects of the welding temperature field developed during the infrared assembly process on the joining properties of glass fiber reinforced polycarbonate composite/polycarbonate with the carbon black. The temperature field and the contact time govern together the quality of the adhesion at the welding interface. It has also been shown:

- A perfect cohesion (a good interface adhesion) has been revealed by a cohesive failure of welded materials with a formation of a weldline between the two materials.

- From the self-diffusion phenomenon or interdiffusion which is supposed occurring only at temperature above the polycarbonate glass temperature $\left(140^{\circ} \mathrm{C}\right)$, the necessary conditions for a complete self-diffusion have not yet been reached. A perfect cohesion was not established even if the first condition of a welding temperature realized above the glass transition temperature of the polycarbonate was achieved. The welding temperature should be increased to obtain a better cohesion of the welding interface and a perfect chain entanglement. The calculated quadratic distance of diffusion was inferior to the mean square end-to-end distance of the polycarbonate at the referenced

$\left(4.88 \times 10^{-17} \mathrm{~m}^{2}<\mathrm{R}_{\mathrm{g}}^{2}=4.06 \times 10^{-16} \mathrm{~m}^{2}\right)$.

temperature

- The calculation of the quadratic distance of diffusion through the thickness showed that under this temperature, the probability of self-diffusion at the interface decreases rapidly.

In future works (next this paper), more quantitative mechanical tests will be carried out in order to confirm microstructural analysis of the failure modes (qualitative observations). Furthermore, the molecular diffusion at polymer interface can be also correlated to the mechanical strength of the weldline. A coupling between the welding process parameters and the mechanical properties of the weld seam may be achieved.

\section{References}

[1] Akué Asséko AC, Cosson B, Schmidt F, Le Maoult Y, Lafranche E. Analytical and numerical modeling of light scattering in composite transmission laser welding process. Int J Mater Form 2015;8:127-35.

[2] Akué Asséko AC, Cosson B, Schmidt F, Le Maoult Y, Gilblas R, Lafranche E.
Thermal Modeling in composite transmission laser welding process: light scattering and absorption coupling. Key Eng Mater 2014;611-612:1560-7.

[3] Akué Asséko AC, Cosson B, Schmidt F, Le Maoult Y, Lafranche E. Laser transmission welding of composites-Part A: thermo-physical and optical characterization of materials. Infrared Phys Technol 2015;72:293-9.

[4] Cole PJ, Macosko CW. Polymer-polymer adhesion in melt-processed layered structures. J Plast Film Sheeting 2000;16:213-22.

[5] Wu S. Polymer interface and adhesion, technology \& engineering. 1982.

[6] Macedo SC, Lafranche E, Martins CI, Douchain C, Roux C, Krawczak P. Thin wall injection-overmoulding of polyamide6/polypropylene multilayer parts: influence of processing conditions on thermomechanical properties of layer assembly. Int J Mater Prod Technol 2016:52.

[7] Lamnawar K, Maazouz A. Rheological modelling of the diffusion process and the interphase of symmetrical bilayers based on PVDF and PMMA with varying molecular weights. Rheol Acta 2012;51:691-711.

[8] UD K, Kausch HH, Williams JG. Fracture mechanics studies of crack healing and welding of polymers. J Mater Sci 1981;16:204-10.

[9] de Gennes PG. Reptation a polymer chain presence fixed obstacles 1971;55: 572.

[10] Doi M, Edwards SF. The theory of polymer dynamics. Oxford Science Publications; 1986.

[11] Butler Christine A, Mccullough Roy L. An analysis of mechanisms governing fusion bonding of thermoplastic composites. J Thermoplast Compos Mater 1998;11(4):338-63.

[12] Kim YH, Wool RP. A theory of healing at polymer-polymer interface. Macromolecules 1983;16:1115-20.

[13] Lamnawar K, Maazouz A. Rheological study of multilayer functionalized polymers: characterization of interdiffusion and reaction at polymer/polymer interface. Rheol Acta 2006;45:411-24.

[14] Lamnawar K, Baudoin A, Maazouz A. Interdiffusion/reaction at the polymer/ polymer interface in multilayer systems probed by linear viscoelasticity coupled to FTIR and NMR measurement. Eur Polym J 2010;46:1604-22.

[15] Wang XC, Sanchez Isaac C. Welding immiscible polymers with a supercritical fluid. Langmuir 2007;23:12192-5.

[16] Ezekoye OA, Lowman CO. Polymer weld strength prediction using a thermal and polymer chain diffusion analysis. Polym Eng Sci 1998;38:976.

[17] Wise RJ. Thermal welding of polymers. Cambridge England: Abington Publishing, Victoire Press Ltd; 1999. p. 37.

[18] Fundamentals of adhesion Wool RP, O' Connor KM. J Appl Phys 1981;52.

[19] Meka P, Stehling F. Heat sealing of semicrystalline polymer films I. Calculation and measurement of interfacial temperature: effect of process variables on seal properties. J Appl Polym Sci 1994;51:89-103.

[20] Graessley WW. Some phenomenological consequences of the Doi-Edwards theory of viscoelasticity. J Polym Sci Part B 1980;18(1):27.

[21] Mairagouna MO. Approche probabiliste du comportement mécanique des thermoplastiques assemblés par soudage laser. 2012. PhD thesis, Ecole des Mines de Paris.

[22] Edwards SF. Statistical mechanics with topological constrains: I. Proc Phys Soc 1967:91(3):513.

[23] Buesche F. Physical properties of polymers. New York: Interscience Publishers; 1980.

[24] Sukmin LEE, Jung Goo LEE, Hosull LEE. The single chain properties of the bisphenol a polycarbonate by the rotational-isomeric-state Monte Carlo method. Polym J 2001;33(9):685-9.

[25] Osswald TA, Rudolph N. Polymer rheology: fundamentals and applications. Cincinnati USA: Hanser Publications; 2014. p. 70. 